\title{
Evaluating Vehicular Delay Cost of Congested Road Networks in Akure Ondo State, Nigeria
}

\author{
Joseph Oyedepo Olugbenga ${ }^{1, *}$ and Abayomi Afolayan ${ }^{2}$ \\ ${ }^{1}$ Department of Civil and Environmental Engineering, \\ Federal University of Technology, Akure, Nigeria \\ ${ }^{2}$ Department of Civil Engineering, Federal Polytechnic Ede, Nigeria
}

\begin{abstract}
Estimate of the impact of congestion such as economic and productivity loss was evaluated along three selected routes namely $R A, R B$ and $R C$ in Akure using cost and delay. Travel speed, and Average Daily Traffic (ADT) were measured using cine camera; while fuel consumption was measured per litre using the vehicles fuel gauge. The annual person hours of delay (APHD) of $626.25 \mathrm{hrs,} 918.51 \mathrm{hrs}$ and $140.91 \mathrm{hrs}$ was obtained for route A, B and $C$ respectively. The daily wasted fuel cost for vehicle on $R A, R B$ and $R C$ are $\$ 785.83 /$ day, $\$ 959.9 /$ day and $\$ 130.5 /$ day respectively, while $\$ 6,506.42$ / day, $\$ 7,676.63$ and $\$ 2,110.92$ was obtained for total delay cost $(T D C)$ on the RA, RB and RC. Also, fuel wasted associated with congestion for RA, RB and RC are 1,642,352.40 naira per year, 1,937,735.8 naira per year, and 532,838.80 naira per year respectively; this amount to economic loss. Provision of effective public transit, efficient off-street parking system, and enforcement of traffic rule and regulation were recommended as a panacea to traffic congestion problem in the study area.
\end{abstract}

Keywords: Traffic congestion, Cine camera, Travel speed, Average Daily Traffic, Public transit, Enforcement,

\section{Introduction}

Traffic congestion refers to the incremental costs resulting from interference among road users [1]. It is travel time or delay in excess of that normally incurred under light or free flow travel conditions [2]. Congestion is defined as occurring on a freeway when the average speed drops below $56.3 \mathrm{~km} / \mathrm{hr}$ for 15 minutes or more on a typical weekday [3]. Traffic congestion is a major transportation problem besetting urban area; it arises when a roadway system approaches vehicle capacity, resulting in numerous negative impacts ranging from increase fuel consumption, increase travel time, energy loss and environmental pollution among others. It also reduces mobility, increases driver stress and vehicle maintenance costs [4]; [1]. The emission of greenhouse gases (GHG) and excessive consumption of energy resources is a global problem, due to both, its causes and consequences [5].

The transport sector is one of the largest emitters despite the advances in the field of engines technology. According to statistics provided by the European Environment Agency [6], road transportation sector has begun to reduce their emission of GHG; but still contributes to about $93 \%$ of the emissions attributable to the transportation sector representing approximately $20.4 \%$ of the total emission. In the U.S., the contribution percentage of road transportation to total GHG emissions is even higher, reaching almost 22\% [7]. Also, great amount of fuel consumption and GHG and pollutants emissions from road transportation sector are concentrated in metropolitan areas. In fact,

\footnotetext{
* Corresponding author. Tel.: +234-803-345-7639

E-mail address: oyedepoo@yahoo.co.uk
}

Manuscript History:

Received 3 April, 2016, Revised 20 September, 2016, Accepted 23 September, 2016, Published 30 September, 2016

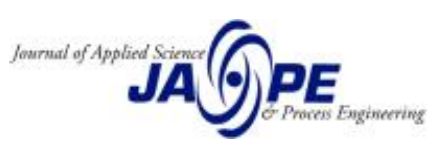


according to the European Environmental Agency, metropolitan areas account for $40 \%$ of the total $\mathrm{CO}_{2}$ produced by the road transportation sector [8].

Traffic demand has been increasing for years within the town and will continue to do so in the future. Over two decades, there has been increase in vehicular population; statistic revealed that private car registration increased from 81000 to 800000 in 1992 and commercial vehicle registration increased from 5200 to 625000 an increase of $888 \%$ and $1,102 \%$ respectively [9], this result into conflicting road uses between vehicle and pedestrian. The delay means lost time, missed opportunities, frustration, lost worker productivity, waste fuel, waste of personal resources and increased cost which have negative implications for the economic development of the country.

Measuring congestion thus provide an understanding of this phenomenon, which in turn will assist transportation professionals, policy makers and the public in effective communicating problems and developing necessary improvement; evaluating of mobility levels also allow for comparisons between transportation systems performance. Hence, this study evaluates the car delay cost on congested road network in Akure, Ondo State, which will help in transportation planning and formulate policy in effective management of the road network in the study area.

\section{Literature Review}

Transportation is an activity of life processes and seeks to provide access to various activities that satisfy mobility needs of humankind [10]. An effective transportation system is significantly important in sustaining economic growth in contemporary economies since it provides linkages between different parts of the country and the global world [11]. An effective urban transport fulfils the demand for accessibility within cities [12]. However, congestion is one of the key operational attributes to assess and evaluate overall highway performance. It reflects slowness and immobility, due to traffic crowding and accumulation.

Congestion can be recurrent (regular, occurring on a daily, weekly or annual cycle) or nonrecurrent (traffic incidents, such as accidents and disabled vehicles). Accordingly, congestion can be perceived as unavoidable consequences of scarce transport facilities such as road space, parking area, road signals and effective traffic management [6]. They argue that urban congestion mainly concerns two domains of circulation, passengers and freight which share the same infrastructure. Traffic congestion condition on road networks occurs as a result of excessive use of road infrastructure beyond capacity, and it is characterised by slower speeds, longer trip hours and increased vehicular queuing. Traffic congestion occurs when the volume of vehicular traffic is greater than the available road capacity, a point commonly referred to as saturation [13]. Congestion is a non-linear function, so as a road approaches its maximum capacity, small changes in traffic volumes can cause proportionately larger changes in congestion delays.

In developing countries, most cities often suffer from chronic highway congestion, echoed by poor mobility and accessibility, significant economic waste, adverse environmental impact and safety problems [1]. Texas Transportation Institute [2] affirm that "Growing congestion in the transportation network poses a substantial threat to the economy and to the quality of life of millions of people, each year, America are paying billions of dollars in term of cost of time, productivity and wasted energy".

Traffic congestion is a widely recognized transport cost. It is a significant factor in transport system performance evaluation and affects transport planning decisions. As a road reaches its capacity, each additional vehicle imposes more total delay on others than they bear, resulting in economically excessive traffic volumes. Vehicle users both bear and impose congestion costs [14]. Traffic congestion costs consist of incremental delay, vehicle operating costs (fuel and wear), pollution emissions and stress that result from interference among vehicles in the traffic stream, particularly as traffic volumes approach a road's capacity Its impacts can be measured based on 
roadway volume to capacity ratios $(\mathrm{V} / \mathrm{C})$. A V/C less than 0.85 is considered under-capacity, 0.85 to 0.95 is considered near capacity, 0.95 to 1.0 is considered at capacity, and over 1.0 is considered overcapacity.

The present study considered the assessment of traffic congestion situation and its value in term of environmental impact, economic cost (fuel and time wastage) of traffic congestion on ObaAdesida-Oyemekun a major road network in Akure Ondo State Nigeria.

\section{The Study Area}

Akure the capital city of Ondo State with a population of 387,087 according to 2006 census, is one of the fastest growing urban settlements in the South Western region of Nigeria. It is located on latitude $70^{\circ} 20^{\prime} \mathrm{N}$ and longitude $50^{\circ} 15^{\prime \prime} \mathrm{E}$. The existing land use is characterized by a medium density of structure within the inner core areas. Akure is composed mainly of residential areas forming over $90 \%$ of the developed area but additional activities such as warehousing; manufacturing, workshops and other commercial activities are commonly located within the residential neighborhoods. Over the years, the number of vehicles on its roads had increased greatly due to increasing socioeconomic activities. Increase in infra-structural facilities such as housing, electricity, water supply and transportation caused rural -urban migration that imposed serious strains on existing transport infrastructure brought about various traffic problems. The natural pattern of development is linear along its main roads; Oyemekun-Oba Adesida road and Arakale-Oda road. These roads connect other street roads from Aiyedun, Isolo, Araromi, Oke-Ijebu, Elerinla, Fanibi, Isikan and Adegbola residential areas.

In Akure metropolis, unsignalized intersections are the most common forms of intersection where it is controlled by Stop and Yield signs. The traffic composition in the metropolis is mixed comprising of motorcycles, taxis, minibuses, Lorries and trucks (trailers); however, the traffic composition of Akure is dominated by taxis, motorcycles (Okadas) and minibuses, [15]; while the vehicular analysis carried out by [16] show that cars, motorcycles, buses, 2 axle, and 3 axle vehicle constitute $49.82 \%, 39.87 \%, 9.37 \%, 0.73 \%$ and $0.21 \%$ respectively. .Figure 1 is the street network map of Akure.

\section{Methodology}

Field studies were conducted on three major road networks converging at the Akure town centre; they are Oyemekun - Oba Adesida road (RA), Araromi-Akure City Hall road (RB) and Oba Adesida - Akure City (RC), being critical to traffic flow in the study area. Traffic parameters were metered using cine camera placed at an elevated vantage point from the road section during the morning and evening peak periods between 7:30-8:30 am and 4:30-5:30 pm respectively and off-peak period between 11:30 am-12:30 pm during week days. Data on speed (Vs), density (K), traffic volume (q), and delay (da) were meticulously extracted from the cine camera by replaying it. Speed was measured by taking the travel time as vehicles traversed a short measured distance along the intersection approaches. Density was measured by counting the number of vehicles occupying a given section of the roadway while replaying the cine-camera. The control delay was measured by taking note of how long a vehicle waited at a particular approach before having the right-of-way. 


\section{Results and Discussion}

Table 1 is the summary of traffic data collected for the selected route, while Table 2 summaries the vehicle hour of delay, fuel wastage and congestion cost for the study area.

Table 1: Summary of Traffic Data for the Selected Route

\begin{tabular}{|c|c|c|c|c|c|c|c|c|c|}
\hline $\begin{array}{c}\text { Vehicle } \\
\text { Type }\end{array}$ & \multicolumn{2}{|c|}{$\begin{array}{c}\text { Free Flow Speed } \\
(\mathbf{k m} / \mathbf{h r}) \text { Route }\end{array}$} & \multicolumn{2}{c|}{$\begin{array}{c}\text { Congested Speed } \\
(\mathbf{k m} / \mathbf{h r})\end{array}$} & \multicolumn{3}{c|}{ VKT (KIN) } \\
& \multicolumn{3}{|c|}{} & \multicolumn{2}{c|}{ Route } \\
\hline & $\mathrm{A}$ & $\mathrm{B}$ & $\mathrm{C}$ & $\mathrm{A}$ & $\mathrm{B}$ & $\mathrm{C}$ & $\mathrm{A}$ & $\mathrm{B}$ & $\mathrm{C}$ \\
\hline Car/taxi & 47 & 35 & 41 & 25 & 17 & 18 & 1702 & 1552 & 232 \\
\hline
\end{tabular}

Typical Calculation Procedure for Route A (RA) is as follows:

Peak period VKT $=$ Daily VKT $* \mathrm{X}$

Where: VKT is the arterial street vehicle kilometre of travel = Average Daily Traffic.

$\mathrm{X}=\mathrm{A}$ fraction of (VKT) taken as 0.45

VKT for $\operatorname{Car} /$ Taxi $=\frac{1702}{12} \times 0.45=64$

$$
V H D=\frac{(V K T)_{c}}{(T S)_{c}}-\frac{(V K T)_{c}}{(T S)_{f}}
$$

Where: VHD = Vehicle Hours of Delay; TS = Travel Speed; $(\text { VKT })_{\mathrm{c}}=$ Congested VKT; $(\mathrm{TS})_{\mathrm{c}}=$ congested TS; $(\mathrm{TS})_{\mathrm{f}}=$ free flow TS

VHD for Car $/$ Taxi $=\frac{(64)}{(25)}-\frac{(64)}{(47)}=1.2 \mathrm{hr}$

$$
A P H D=(V H D) d x N v \times N w
$$

Where: APHD = Annual person hours of delay; $(\mathrm{VHD})_{\mathrm{d}}=$ Daily Vehicle hours of delay;

$\mathrm{N}_{\mathrm{v}}=$ No. of person per vehicle; and $\mathrm{N}_{\mathrm{w}}=$ No. of working days per year

APHD for Car $/$ Taxi $=1.2 \times 1 \times 260=312$ hrs

Note: Proportion of Car/Taxi is 49.82\% Oyedepo, (2014)

APHD for $R A=\frac{312 \times 100}{49.82}=626.25 \mathrm{hrs}$ 


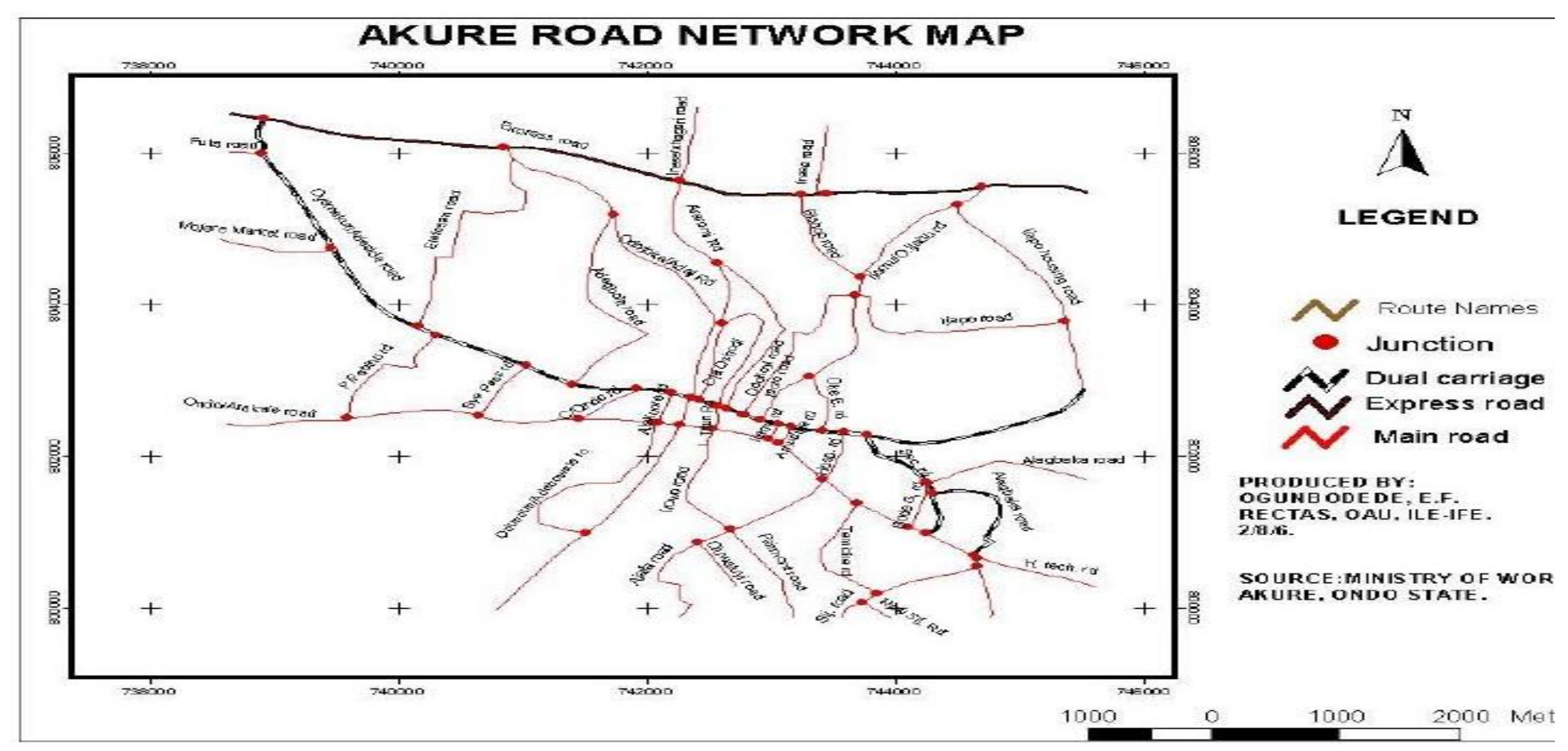

Figure 1: The Street Network Map of Akure 
Wasted fuel is found based on the change fuel economy and is expressed as follows:

$$
(F W) d=\frac{(V H D)}{F E} \times A P P S
$$

Where: $(\mathrm{FW})_{\mathrm{d}} \quad=$ Daily wasted fuel; $\mathrm{FE}=$ Average fuel economy; and

APPS $=$ Average peak period system speed

$$
(F W) \text { d for Car/Taxi } \quad=\frac{1.2}{10} \times 22.5=2.7 \text { lit } / \text { day }
$$

Cost of operating commercial vehicle in congested conditions is calculated as follows:

$$
\begin{gathered}
(D P D C) d=H d x P v x V x \\
(D V D C) d=(V H D) d x \text { APPS } x V y
\end{gathered}
$$

here: $(D P D C)_{d}=$ Daily passenger vehicle delay cost; $\mathrm{H}_{\mathrm{D}}=$ Passenger vehicle hours of delay;

$P_{v}=$ Values of person in Naira per hour say $\$ 500 ; V_{X}=$ Vehicles occupancy in person/vehicle;

$(\mathrm{VDC})_{\mathrm{d}}=$ Vehicle delay cost; VHD= Daily vehicle-hours of delay in hour;

APPS = Average peak period system speed $\mathrm{V}_{\mathrm{y}}=$ Vehicle operating cost

$(D P D C) d$ for Car $/$ Taxi $\quad=1.2 \times 500 \times 1=\# 600 /$ day

(VDC)d for Car/Taxi $\quad=(1.2 \times 22.5 \times 11000) / 12=\$ 2,250 / h r$

Fuel cost was calculated by assessing the peak period speed, average fuel economy with the vehicle hours of delay:

$$
(F W) c=(F W) d x F c
$$

Where: $(\mathrm{FW})_{\mathrm{c}}=$ Daily fuel cost; $\mathrm{F}_{\mathrm{c}}=$ Cost of fuel per litre; and

Note: Prevailing fuel cost in the study area is $\$ 145$ per litre

$\left(\mathrm{F}_{\mathrm{W}}\right)_{\mathrm{d}}=$ Daily wasted fuel in litre

$(F W)$ c for Car $/$ Taxi $=2.7 \times 1145=\$ 391.5 /$ day

Note: Proportion of Car/Taxi is $49.82 \%$ Oyedepo, (2014) 
Daily wasted fuel for vehicle on $R A=5.4$ litrs/day

Daily Wasted Fuel cost for Vehicle on $R A=\frac{\$ 391.5 \times 100}{49.82}=\$ 785.83$

$$
\text { Total Delay Cost }(T D C)=D P D C+D V D C+(F W)_{0}
$$

Where: TDC $=$ Total delay cost; DPDC $=$ Daily passenger vehicle delay cost; $\mathrm{VDC}=$ Vehicle delay cost,

$(\mathrm{FW})_{\mathrm{c}}=$ Daily fuel cost

Total Delay Cost $(T D C)$ for $R A=\$ 600+\$ 2,250+\$ 391.5=\$ 3,241.5$

Total Delay Cost(TDC) for Vehicle on $R A=\frac{\$ 3,241.5 \times 100}{49.82}=\$ 6,506.42$

Similarly, the analysis for RB and RC were carried out using the same procedure.

Remark: The APHD of $626.25 \mathrm{hrs}, 918.51 \mathrm{hrs}$ and $140.91 \mathrm{hrs}$ was obtained for route A, B and C respectively. The daily wasted fuel cost for vehicle on RA, RB and RC are $\$ 785.83 /$ day, $\$ 959.9 /$ day and $\$ 130.5$ /day respectively, while $\$ 6,506.42$ / day, $\$ 7,676.63$ and $\$ 2,110.92$ was obtained for TDC on the RA, RB and RC. Also, fuel wasted associated with congestion for RA, RB and RC are $1,642,352.40$ naira per year, 1,937,735.8 naira per year, and 532,838.80 naira per year respectively.

The results show considerable increase in fuel consumption under congested traffic conditions. However, huge amount from with fuel wastage resulting from congestion contributes to economic loss of an individual and the country at large. 
Table 2.0: Summary of Vehicle Hour of Delay, Fuel Wastage and Congestion Cost for the Study Area

\begin{tabular}{|c|c|c|c|c|c|c|c|c|c|c|c|c|c|c|c|c|c|c|c|c|c|}
\hline \multirow[t]{2}{*}{$\begin{array}{c}\text { Vehicle } \\
\text { Type }\end{array}$} & \multicolumn{3}{|c|}{$\begin{array}{c}\text { VHD (hr) } \\
\text { Route }\end{array}$} & \multicolumn{3}{|c|}{$\begin{array}{c}\text { APHD (hr) } \\
\text { Route }\end{array}$} & \multicolumn{3}{|c|}{$\begin{array}{c}\text { Daily Fuel Wasted } \\
\text { (ltr) } \\
\text { Route }\end{array}$} & \multicolumn{3}{|c|}{$\begin{array}{c}\text { DPDC (N) } \\
\text { Route }\end{array}$} & \multicolumn{3}{|c|}{$\begin{array}{c}\text { DVDC (N) } \\
\text { Route }\end{array}$} & \multicolumn{3}{|c|}{$\begin{array}{c}\text { DFC (N) } \\
\text { Route }\end{array}$} & \multicolumn{3}{|c|}{$\begin{array}{l}\text { TDC (N) } \\
\text { Route }\end{array}$} \\
\hline & A & B & $\mathrm{C}$ & A & B & $\mathrm{C}$ & A & B & $\mathrm{C}$ & A & B & $\mathrm{C}$ & A & B & C & A & B & $\mathrm{C}$ & A & B & $\mathrm{C}$ \\
\hline Car/taxi & 1.20 & 1.76 & 0.27 & 626.25 & 918.51 & 140.91 & 5.40 & 6.62 & 0.90 & 600 & 600 & 600 & 2250 & \begin{tabular}{|l|}
2750 \\
\end{tabular} & 371 & 297 & 363 & 50 & $6,316.74$ & $7,452.83$ & $2,049.38$ \\
\hline
\end{tabular}




\section{Concluding Remarks}

The need to solve the problem of traffic congestion along the studied area cannot be over emphasised. The study shows that recurrent congestion occurs on the road under consideration due to factor such as inefficient capacity, unrestrained demand, ineffective capacity management, on street trading and defective law enforcement. The study also revealed that the alarming figure of cost due to congestion estimated in the studied area is as a result of poor linkage between transportation and land use planning, sitting of large market close to the important feeder road, loading and off loading characteristics of taxi drivers around the intersection and more importantly pedestrian traffic. The report estimates that peak period travelers lost an average of $561.89 \mathrm{hrs}$ and wasted about 1,119.73 litres of fuel per year. Strategies such as provision of effective public transit, provision and efficient management of off-street parking, and enforcement of traffic rule and regulation should be adopted in the study area. Also, the effects of congestion on fuel consumption should be taken into consideration by the route planners.

\section{Acknowledgements}

We hereby acknowledge the Transportation Engineering Students for assisting in the traffic data collection.

\section{References}

[1] Victoria Transport Policy Institute (VTPI) (2005): Congestion reduction strategies: identifying and evaluating strategies to reduce congestion, in: Online TDM Encyclopaedia, Victoria, British Columbia, Canada: Victoria Transport Policy Institute.

[2] Lomax, S.T.T.; Turner, S.; Shunk, G.; Levinson, H.S.; Prat, R.H.; Bay, P.N.; Douglas, G.B. (1997): Quantifying congestion, Transportation Research Board, Vol. 1, NCHRP Final Report 398. Washington, D.C.:. Pp 108 .

[3] Varaiya, P. (2001): Freeway Performance Measurement System: Mining Loop Detector Data, Journal of the Transportation Research Board, Vol. 1748

[4] The United States Environmental Protection Agency (2013): Inventory of U.S. Greenhouse Gas Emissions and Sinks: 1990 - 2011. EPA 430-R-13-001, U.S. Environmental Protection Agency, Washington D.C.;

[5] Rodrigue, J.P., Comtols, C. and Slack, B. (2009): The Geography of Transportation System Second Edition; Taylor \& Francis e-Library;

[6] European Environment Agency (2013) Annual European Union Greenhouse Gas Inventory 1990-2011 and Inventory Report 2013. No 8/2013, European Environment Agency, Copenhagen;

[7] Texas Transportation Institute (TTI) (2005): The Keys to Estimating Mobility in Urban Areas: Applying Definitions and Measures That Everybody Understands, Texas Transportation Institute.

[8] European Environment Agency. The European Environment. State and Outlook 2010. Urban Environment. Publications Office of the European Union. ISBN 978-92-9213-151-27, Copenhagen;

[9] USDOT BTS (1997): Transportation Statistic Annual Reports. US Department of Transportation Bureau of Transportation Statistics

[10] Arasan, T.V. (2012):Urban Transportation systems planning. Unpublished Hand Book presented at Short Term Course organized by Kwame Nkrumah University of Science and Technology and Indian Institute of Technology Madras, Accra.

[11] Eddington, R. (2006): Transport's Role in Sustaining the UK's Productivity and Competitiveness. The Eddington Transport Study Main Report: UK Department for Transport, London.

[12] Okoko, E. E. (2006). Quantitative techniques in urban analysis.Kraft Books Limited, Ibadan

[13] Downie, A. (2008): The World Worst Traffic Jams time. Available at: http://www.time/world/article/0,8599,1733872,00.html. (Retrieve on 28th February,20 12

[14] FHWA (2006): Travel Time Reliability: Making It There On Time, All The Time, US Department of Transportation;

[15] Owolabi, A. (2009). Paratransit Modal Choice in Akure, Nigeria. Applications of Behavioral Models. Institution of Transporrtation Engineers Journal, Vol. 79, No. 1, Pp 54-58.




[16] Oyedepo, O. J. (2014): Predictive Modelling of Traffic Flow at Urban Road Intersections: A Case Study of Akure Metropolis, Nigeria; Unpublished Ph.D Thesis, School of Postgraduate Studies, The Federal University of Technology Akure Nigeria. 